\author{
Adele Fabbrocini ${ }^{1}$, Maria Grazia \\ Volpe $^{2}$, Elena Coccia ${ }^{3}$, Raffaele \\ D’Adamo $^{1}$ and Marina Paolucci ${ }^{2,3 *}$ \\ ${ }^{1}$ ISMAR - CNR UOS Lesina, via Pola 4, 71010 \\ Lesina (FG), Italy \\ ${ }^{2}$ ISA - CNR Via Roma 52, 83100 Avellino, Italy \\ ${ }^{3}$ Department of Science and Technologies, University \\ of Sannio, Via Port'Arsa, 11, 82100 Benevento, Italy \\ Dates: Received: 28 August, 2015; Accepted: 12 \\ October, 2015; Published: 14 October, 2015 \\ *Corresponding author: Prof. Marina Paolucci, \\ Department of Sciences and Technologies, Via \\ Port' Arsa, 1182100 , Benevento, Italy, Tel: 0039- \\ 0824-305126; Fax: 0039-0824-23013; E-mail: \\ paolucci@unisannio.it \\ www.peertechz.com \\ ISSN: 2455-8400
}

Keywords: Biopolymers; Sea-urchins; Paracentrotus lividus; Feeding; Gonads

\author{
Research Article
}

\section{Agar-based Biocomposites slow down Progression in the Reproductive Cycle Facilitating Synchronization of the Gonads of Reared Specimens of Paracentrotus lividus}

\section{Abbreviations}

HE: High degree of Esterification; LE: Low degree of Esterification; A-AP(he): Agar 2\% -Apple Pectin (he) 1\%; A-AP(le): Agar 2\% - Apple Pectin (le) 1\%; G-A: Gellan 1\% - Agar 1\%; G-AA: Gellan 1\% -Alginic Acid 1\%; G-AP(le): Gellan 1\% -Apple Pectin (le) 1\%; CP(le): Citrus Pectin (le) 3\%; AP(le): Apple Pectin (le) 3\%

\section{Introduction}

The rapid expansion of sea urchin farming has increased the demand for formulated feed specifically developed for echinoids' needs. It has been widely demonstrated that prepared diets increase both somatic growth and gonad yield with respect to natural food [1-4].

A great deal of information on rearing and feeding protocols is available for many species of sea urchin [4-7]. There is however a need to refine these techniques, tailoring them according to the needs of the single species in the various phases of its life cycle, in order to overcome the weaknesses still preventing broader adoption of echiniculture, especially regarding Mediterranean species [8-11]. Moreover, sea urchins, particularly Paracentrotus lividus, are widely used in laboratory research [12], and a feed whose composition could be each time easily modified according to the research purposes might be a helpful alternative to generically basic-formulated feed.

Research into the formulation of feed for sea urchins must take account not only feed effects on gonad yield and sensory quality but also feed firmness and palatability, in order to improve the ingestion rate and consequently the quantity of ingested nutrients. Another crucial issue is feed stability. Sea urchins are grazers and in natural conditions Paracentrotus lividus specimens are reported to feed mainly on fleshy algae and suspended organic particles [13,14]. In confined conditions, they have shown to need at least 2-3 days to eat the feed offered $[12,15]$, also, a discontinued food distribution gave the best results in terms of gonad production and waste removal [16]. Thus, in order to limit nutrient loss and facilitate rearing management, addition of binders to the feed has been considered [17].

Although much of the research into sea urchins reared in 
confined conditions has focused on the formulation of prepared feed, relatively few published studies have examined the effects on urchin gonad growth of the nature and concentration of the binder. In many echinoid species, gelatin-based pellets lead to greater growth $[18,19]$ and a higher gonad yield [1,20-23]. Moreover, pellets based on agar [24], sodium alginate [25,26], guar gum and corn starch [26] have been shown to give better results in terms of gonad indices than natural diets. Recently, the effectiveness of agar-based pellets for gonad growth and gamete production in Paracentrotus lividus were tested with encouraging results [11].

Thus, binders are essential for the manufacture of formulated feed, and research is always on the look-out for new solutions based on eco-friendly, sustainable and cost-effective materials. Carbohydrates are natural biomolecules whose molecular diversity includes structures and characteristics with a large array of functions of great significance, making them suitable candidates as binders. Carbohydrates create three-dimensional networks or hydrogels that entrap nutrients and are sustainable and biodegradable. In the food industry, long carbohydrate polymers or polysaccharides play important roles as phytocolloids as well as emulsifying agents [27]. Polysaccharide binders in animal feed have been tested for water stability and growth performance in aquatic species with conflicting results [17-28]. Consistent results have been obtained regarding improved growth rates in crayfish fed on pectin-based pellets [29-31].

In this study a number of polysaccharide binders were mixed with nutrients to generate biocomposites with prolonged firmness that were then tested in sea urchin rearing conditions, including up to two weeks' immersion in water. Three polysaccharides from macroalgae (alginic acid, agar and gellan) were chosen due to their good three-dimensional networking properties and their presence in the sea urchins' natural diet. Tests were also conducted using pectin, a major component of terrestrial plant cell walls, whose three-dimensional networking properties depend on the degree of chemical modification during the extraction process. In this study, polysaccharides, either alone or in combination, were mixed with varying percentages of the selected nutrients or tested for consistency and palatability trials in presence of urchins. Moreover, the network strength of biocomposites was evaluated in terms of nutrient release and water uptake.

\section{Materials and Methods \\ Biocomposite formulation and preparation}

The following biopolymers were employed: sodium alginate, agar and gellan, supplied by Sigma (St. Louis, MO, USA), and Low Ester Apple Pectin (Pectin Classic AU 701, mw 55,000 Da), High Ester Apple Pectin (Pectin Classic AU 202, mw 75,000 Da), Low Ester Citrus Pectin (Pectin Classic CU 701, mw 70,000 Da) and High Ester Citrus Pectin (Pectin Classic CU 201, mw 85,000 Da), (Herbstreith \& Fox Pektin-Fabriken, Neuenbuerg, Germany). Biocomposites were first produced with varying percentages of feed ingredients (5-25\%) and polymers (2-3\%), either alone or in blends of two types, adding $\mathrm{CaCl}_{2}(0.05-1 \%)$ to all biopolymers as a networking agent. All possible combinations were tested in order to select those with the best consistency as an indication of the network strength. The nutrient composition of biocomposites is reported in details in Table 1 and was formulated taking into account what reported in the current literature on sea urchin rearing in confined conditions [32].

Biocomposites were manufactured by the following procedure: each biopolymer or mixture of two biopolymers in powder form was dissolved to the desired percentage in tap water and heated to boiling point on a magnetic plate, stirring constantly. The solution was allowed to boil for few minutes and was then cooled at room temperature (RT) to a temperature of $45 \pm 5{ }^{\circ} \mathrm{C}$. Nutrients were ground to a particle size of $<250 \mu \mathrm{m}$ [33] and $\mathrm{CaCl}_{2}$ was then added to the mixture while stirring vigorously [31]. The biocomposite was then poured into Petri capsules and allowed to cool at RT for $12 \mathrm{hrs}$. Consistency was subjectively evaluated using the following scale employed by Pearce et al. [26].

1. very good consistency $=$ biocomposites were not disaggregated and withstood weak pressure;

2. good consistency = biocomposites were not disaggregated, but fell apart with weak pressure;

3. weak consistency $=$ biocomposites were partially disaggregated;

4. inconsistent $=$ biocomposites were completely disaggregated .

Samples with "very good consistency" at the lowest percentages of biopolymer or mixture of biopolymers were selected for further trials.

\section{Sea urchins collection}

Sea urchin specimens (Paracentrotus lividus, Lmk 1816) were carefully hand-collected with the aid of Scuba-diving equipment from a rocky seabed along the Southern Adriatic coast (41 $54^{\prime} \mathrm{N} ; 16^{\circ}$ $10^{\prime} \mathrm{E}$ ), immediately placed in a cooler and carried to the laboratory within one hour. Sea urchins were then measured (horizontal diameter) by caliper $(0.05 \mathrm{~mm}$ accuracy) and specimens with a test diameter of between 30 and $35 \mathrm{~mm}$ excluding spines were selected for the experimental trials. Urchins were acclimated in starving conditions for one week in a recirculating rearing system consisting of rectangular tanks ( $100 \mathrm{~L}$ each; $\mathrm{L} \times \mathrm{W} \times \mathrm{H}: 50 \times 45 \times 45 \mathrm{~cm}$ ). The seawater flow rate was $16 \mathrm{~L} \mathrm{~min}^{-1}$. Abiotic parameters were measured on a daily basis and kept at constant temperature $\left(18 \pm 1{ }^{\circ} \mathrm{C}\right)$, salinity $(36 \% \pm \pm 1), \mathrm{pH}(8.00-8.20)$ and dissolved oxygen (>90\%). The rearing system was kept in a natural photoperiod (from $16 \mathrm{~h} \mathrm{~L}: 8 \mathrm{~h} \mathrm{D}$ to $12 \mathrm{~h}$ $\mathrm{L}: 12 \mathrm{~h} \mathrm{D}$ during the trial). None of the urchins died during the trial.

\section{Palatability and stability trials}

27 sea urchins (starved for three additional days before the start of

Table 1: Feed ingredients used in diet.

\begin{tabular}{|c|c|}
\hline Ingredient & Dry weight (\%) \\
\hline shrimp meal & 19.00 \\
\hline pea meal & 27.00 \\
\hline Corn meal & $24.00-25.00$ \\
\hline Kelp meal & 25.00 \\
\hline Fish oil & 1.80 \\
\hline Mineral mix & 0.10 \\
\hline Vitamin mix & 0.10 \\
\hline
\end{tabular}

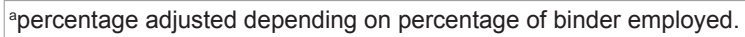


Table 2: Biocomposites selected on the basis of the consistency according to Pearce et al. [26].

\begin{tabular}{|c|c|c|}
\hline $\begin{array}{c}\text { Biocomposite } \\
\text { Acronym }\end{array}$ & $\begin{array}{c}\text { Biocomposite } \\
\text { Composition }\end{array}$ & $\begin{array}{l}\text { Nutrients (\%) } \\
\text { (dry weight) }\end{array}$ \\
\hline A-AP(he)* & Agar $2 \%$-Apple Pectin (he) $1 \%$ & 10 \\
\hline$A-A P(l e)^{\star \star}$ & Agar $2 \%$ - Apple Pectin (le) $1 \%$ & 10 \\
\hline G-A & Gellan $1 \%$ - Agar $1 \%$ & 10 \\
\hline G-AA & Gellan 1\% -Alginic Acid 1\% & 10 \\
\hline G-AP(le)* & Gellan 1\% -Apple Pectin (le) 1\% & 10 \\
\hline Agar & Agar $2 \%$ & 10 \\
\hline $\mathrm{CP}(\mathrm{le})^{*}$ & Citrus Pectin (le) 3\% & 10 \\
\hline $\mathrm{AP}(\mathrm{le})^{*}$ & Apple Pectin (le) 3\% & 10 \\
\hline Gellan & Gellan 2\% & 10 \\
\hline
\end{tabular}

the experiment) were separately placed in gently aerated cylindrical plastic tanks (15 cm diameter, $18 \mathrm{~cm}$ height), each containing 2.5 $\mathrm{L}$ of seawater and one of the nine selected biocomposites (i.e. three replicates for each biocomposite) listed in Table 2. After $24 \mathrm{~h}$ and $48 \mathrm{~h}$, a qualitative evaluation of the consistency of the biocomposites was performed according to Pearce [26] and any eating activity was assessed by visual inspection. In fact, under our rearing conditions, feed not accepted within the first $24-48$ hours proved to have low chances to be grazed later on. The trial was carried out at a temperature of $18 \pm 1{ }^{\circ} \mathrm{C}$ and a salinity of $36 \%$ o \pm 1 ; these parameters were standardized in previous trials, and found to be optimal for Paracentrotus lividus rearing in confined conditions [12,15]. At the end of the trial $(48 \mathrm{~h})$ dry matter loss was evaluated as described in the next section.

\section{Biocomposite swelling and nutrient release in water}

A-AP(he), A-AP(le), Agar, CP(le) and AP(le) biocomposites were selected on the basis of the palatability trials and tested for swelling and nutrient release in water. Three samples for biocomposites $(10 \pm 1$ g) were placed in a beaker of $500 \mathrm{ml}$ of seawater and soaked in static seawater for up to 14 days at a temperature of $18^{\circ} \mathrm{C}$.

For the swelling test, samples were recovered every two days and re-weighed in order to assess weight gain. To evaluate dry matter loss, quantitative analysis was performed by evaporating the water in which the biocomposites were immersed. At time intervals of 2 days, up to 14 days, the amount of nutrients deposited on the bottom was determined by ponderal analysis according to AOAC [34]. This length of long immersion period was tested in the view of reducing as much as possible the rearing system cleaning procedures.

\section{Rearing trial}

Two groups of 15 urchins each were allocated in two tanks and fed for a period of 14 weeks, on two (A-AP(le) and Agar) of the biocomposites tested for palatability and behavior in water after $24 \mathrm{~h}$ and $48 \mathrm{~h}$ of sea urchin. Proximate analysis of the experimental diets is shown in Table 3. Feed was offered in the amount of 5\% nutrients/ biomass/day both the experimental groups and was completely consumed by urchins within 3 days; every fourth day a new dose was added. The rearing system and conditions were those above described, found to be optimal in previous Paracentrotus lividus rearing trials
$[12,15]$, in which high survival and gonad maturation rates were recorded. At the end of the trial the urchins were sacrificed in order to evaluate the gonad index and reproductive stage as described in Fabbrocini et al. [15]. Fifteen urchins coming from the same batch were sacrificed at the beginning of the trial in order to evaluate the gonad index and reproductive stage on $t 0$.

\section{Gonad index}

The sea urchins were allowed to drip for approximately $5 \mathrm{~min}$, weighed $(0.2 \mathrm{mg}$ accuracy) and then dissected; the gonads were extracted and fresh weighed for evaluation of the Gonad Index (GI): $\mathrm{GI}=$ gonad wet weight $(\mathrm{g}) /$ sea urchin wet weight $(\mathrm{g}) \times 100$.

\section{Gonad histological evaluation}

One of the five gonads of each animal was fixed in 10\% formalin, embedded in paraffin, sectioned at $7 \mu \mathrm{m}$ and stained with Mayer's Haemalum/Eosin. The reproductive stage was assigned in accordance with Spirlet et al. [35], stage I (spent with relict gametes - no developing gametes can be observed along the thin acinal wall, but few unspawned gametes to be rebsorbed can be still present); stage II (spent empty - a thin layer of early developing gametes becomes to be evident along the acinal wall, while nutritive phagocytes create a meshwork in the centre of acini); stage III (recovery - a thick meshwork of nutritive phagocytes fills the acini and a layer of developing gametes is present along the acinal wall); stage IV (growing - developing primary oocytes surrounded by nutritive phagocytes can be observed in the ovary, while columns of developing spermatocytes are present in the testes); stage V (premature - developing gametes can be clearly observed, and mature oocytes or spermatozoa begin to accumulate in the centre of the acini); stage VI (mature - gonads are packed with mature gametes, and few developing gametes can be observed); stage VII (spawning - acini present spaces vacated by spawned gametes; developing gametes are still present); stage VIII (post-spawned large amounts of unspawned gametes are still present in the centre of acini, while no developing gametes can be observed).

\section{Statistical analysis}

Considering the marked differences in the GI values, and taking into account that the tank effect can be considered negligible as the rearing system was small-scaled and the rearing conditions were strictly controlled, the differences between the gonad indices recorded at the end of the rearing trial between the two experimental groups (Agar vs A-AP(le)) were determined by Student T test. Prior to analysis, data were arcsine-transformed and tested for normality using Shapiro-Wilk's test and for homogeneity of variance using Cochran's C test. All analyses were performed with the StatSoft, Inc. (2008) STATISTICA data analysis software system, version 8.0. No quantitative analysis of histological preparations was conducted, so that statistical analyses were not performed.

Table 3: Proximate composition of the two tested biocomposites.

\begin{tabular}{|l|c|c|}
\hline Variable & Agar & A-AP(le) \\
\hline Protein \% & 3.06 & 4.05 \\
\hline Fat \% & 0.42 & 0.60 \\
\hline Carbohydrate \% & 14.7 & 14.4 \\
\hline Moisture \% & 81.2 & 80.9 \\
\hline
\end{tabular}




\section{Results}

\section{Biocomposite formulation and preparation}

Biocomposites were produced with varying percentages of feed ingredients (5-25\%) and polymers (2-3\%), either alone or in blends of two types. All possible combinations were tested in order to select those with the best consistency, used as an indicator of the network strength. Consistency was subjectively evaluated using the terminology employed by Pearce et al. [26]. On the basis of their consistency, the biocomposites listed in Table 2 were tested for palatability and stability in presence of sea urchins.

\section{Palatability and stability trials}

A-AP(he), A-AP(le), Agar, CP(le) and AP(le) biocomposites were eaten by the sea urchins, while the others were not attractive, as were not eaten (Table 4). Regarding consistency, only G-A, and Agar kept a "very good consistency" up to $48 \mathrm{~h}$. Gellan lost consistency after a few hours of immersion. All biocomposites, except for G-A and G-AP (le), showed dry matter loss of more than $15 \mathrm{mg} \mathrm{L}^{-1}$ after $48 \mathrm{~h}$ of immersion in the presence of sea urchins, probably as a consequence of eating.

\section{Biocomposite swelling and nutrient release in water}

A-AP(he), A-AP(le), Agar, CP(le) and AP(le) biocomposites that were eaten by the sea urchins in the palatability trials were evaluated for swelling and nutrient release in water (Figures 1,2). Agar showed the best performance with water uptake of less than $0.5 \%$ after 14 days, followed by A-AP(he), A-AP(le), G-A and G-AP(le) (Figure 1). Regarding nutrient release, $\mathrm{A}-\mathrm{AP}(\mathrm{he})$ showed the worst performance, with about $1.5 \%$ loss of nutrients after 2 days of immersion and about $2 \%$ nutrient loss after 14 days of immersion. The nutrient release curves of the other biocomposites were substantially similar, to each other, showing a percentage of less than $0.5 \%$ loss after 8 days and a maximum nutrient loss of $1 \%$ after 14 days of immersion (Figure 2).

\section{Rearing trial}

The GI values recorded after 14-wks of feeding on Agar pellet were twofold in respect of those recorded in both specimens on $t(0)$ and after feeding on A-AP(le) biocomposites (Figure 3).

Gonads were classified into 8 stages in accordance with Spirlet et al. [35], as described in the Material and Methods Section. Since no substantial differences between the frequencies of ovaries and testes were observed, the data were combined for easier discussion of the results. At the beginning of the trial (t0) (Figure 3), most specimens were in spent phase (stage I), with no developing gametes along the thin acinal wall, or in spent empty phase (stage II), with a thin layer of early developing gametes clearly evident along the acinal wall. After 14 weeks of rearing, the gametogenic cycle had progressed, more slowly in A-AP(le)-fed sea urchins (Figure 3). Indeed, about $60 \%$ of the A-AP(le)-fed urchins were still in stages I and II, while the remaining $40 \%$ were at the beginnings of the reproductive cycle (stage III, recovery), with a thick meshwork of nutritive phagocytes across the acini and a layer of developing gametes along the acinal wall. In contrast, about $15 \%$ of the sea urchins fed on Agar were already in premature stage (stage $\mathrm{V}$ ), with the centre of the acini increasingly filled with mature gametes and about $50 \%$ of the reared specimens were in recovery (stage III).

\section{Discussion}

In this study, a formulated diet was produced which varied solely with respect to the added binder or mixture of binders. Alginate, gellan, agar, pectins with different degree of esterification and mixtures of these were tested. Only those biocomposites that showed good consistency characteristics were tested in the presence of sea urchins; moreover, the effectiveness of the biocomposites selected in the second phase was tested on reared urchins.

The results of the network strength trials indicate that alginate yields the poorest biocomposite. Alginate has been found to be an effective binder for formulated diets for Pseudocentrotus depressus [36], but it was employed at a percentage of $30 \%$. This is quite a high percentage and is unlikely that it could be employed for sea urchin feeding on a commercial scale due to both the high cost and lower nutrient levels in the feed [37]. In contrast, our outcome is in agreement with Pearce et al. [26], who reported that alginate at $5 \%$ and dicalcium phosphate at $1.8 \%$ did not allow proper alginate gelation, even after dipping the feed pellets in $5 \% \mathrm{CaCl}_{2}$. In this study a second polymer, gellan, was used to obtain alginate/ $\mathrm{Ca}^{2+}$ biocomposites with a more even structure. Gellan is a bacterial exopolysaccharide commercially prepared by submerged aerobic fermentation from Sphingomonas elodea. In the presence of divalent ions this biopolymer is capable of forming gels that are particularly strong [38]. However, in this study its employment as a binder to generate biocomposites for sea

Table 4: Palatability and stability of tested biocomposites and behavior in water after $24 \mathrm{~h}$ and $48 \mathrm{~h}$ of sea urchin eating. Palatability: plus sign $=$ grazed; minus sign $=$ not grazed. Water turbidity: plus sign = dry matter loss < $15 \mathrm{mg} / \mathrm{l}$. Stability is expressed by consistency evaluation according to Pearce et al [26]: $1-$ very good consistency; 2 - good consistency; 3 - weak consistency; 4 - inconsistent.

\begin{tabular}{|l|c|c|c|c|c|}
\hline & \multicolumn{2}{|c|}{$\mathbf{2 4 h}$} & \multicolumn{2}{|c|}{ P8h } \\
\hline Biocomposite & Palatability & Consistency & + & Consistency \\
\hline A-AP(he) & + & 3 & + & + \\
\hline A-AP(le) & + & 2 & - & + \\
\hline G-A & - & 1 & - & + \\
\hline G-AA & - & 4 & - & + \\
\hline G-AP(le) & - & 2 & + & + \\
\hline Agar & + & 1 & + & + \\
\hline GP(le) & + & 4 & + & + \\
\hline AP(le) & + & 4 & + & + \\
\hline Gellan & - & 4 & - & + \\
\hline
\end{tabular}




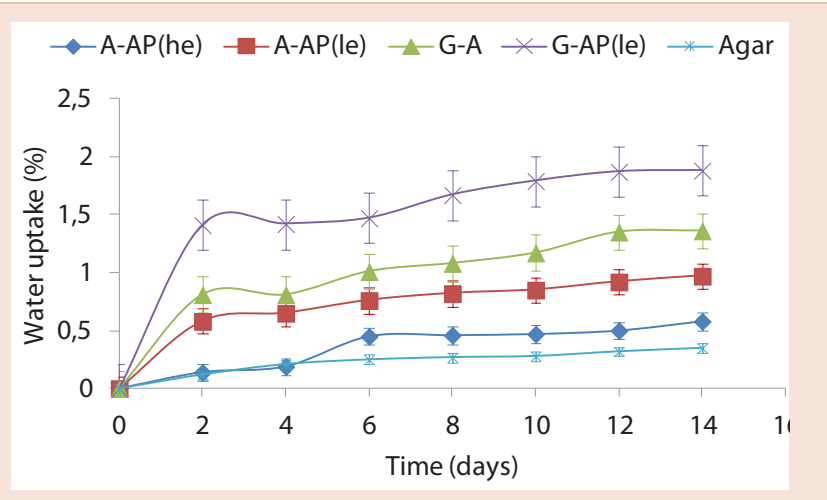

Figure 1: Water retention.

Water retention of biocomposites during 14 days of seawater immersion. $\mathrm{A}-\mathrm{AP}($ he $)=$ Agar $2 \%$-Apple Pectin (he) 1\%; A-AP(le) = Agar 2\% - Apple Pectin (le) 1\%; G-A = Gellan 1\% - Agar 1\%; G-AP(le) = Gellan 1\% -Apple Pectin (le) 1\%; Agar $=$ Agar $2 \%$..

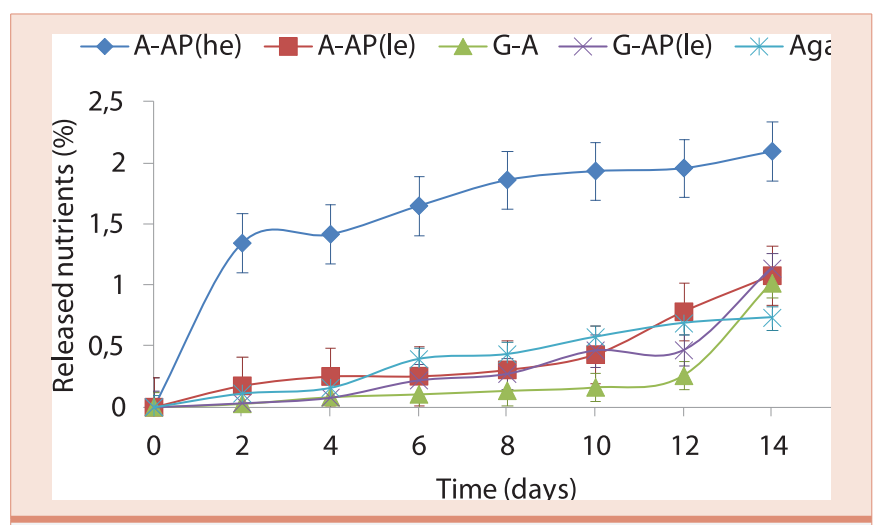

Figure 2: Nutrient release.

Nutrient release of biocomposites during 14 days of seawater immersion. A-AP(he) = Agar 2\% -Apple Pectin (he) 1\%; A-AP(le) = Agar 2\% - Apple Pectin (le) $1 \%$; G-A = Gellan 1\% - Agar 1\%; G-AP(le) = Gellan 1\% -Apple Pectin (le) $1 \%$; Agar $=$ Agar $2 \%$.

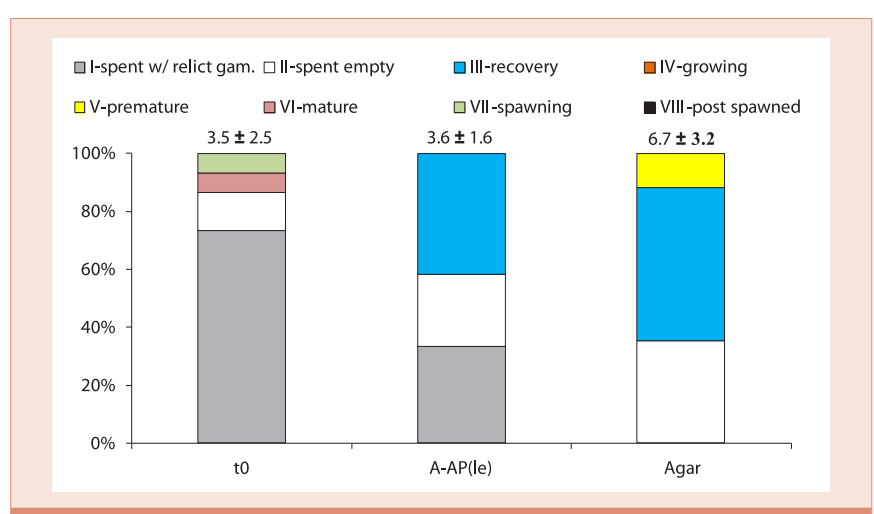

Figure 3: Gonad stages.

Reproductive condition of Paracentrotus lividus gonads at to $(n=15)$ and at end of rearing trial (14 weeks) with the two experimental diets ( $n=15$ treatment -1). Gonad stages are classified in accordance with Spirlet et al. [35]. A-AP(le) = Agar 2\% - Apple Pectin (le) 1\%; Agar = Agar $2 \%$. Values on the bars indicate the relative Gonad Index (Mean \pm SD). urchins did not succeed; the biocomposites were hard but brittle and fell apart easily soon after gelation. When gellan was used in combination with alginate biocomposites it showed good consistency at room temperature, but became inconsistent after a few hours of immersion in water, probably as a consequence of the gel rigidity induced by the gellan, which favors breakdown in water, impairing hydration and therefore swelling. In contrast, when gellan was used in combination with agar and/or pectin the biocomposites showed good consistency in seawater for 14 days. However, biocomposites made with gellan were not appreciated by sea urchins and they were therefore discarded.

Pectins are highly versatile polymers, with a wide range of applications. The properties of pectin depend on the degree of esterification. Pectins in nature possess a low degree of esterification, which increases the number of $\mathrm{H}$ bonds between chains and therefore leads to a strong network. In contrast, a high degree of esterification lead to a weaker network. Similar to alginate, pectins with a low degree of esterification can react with calcium ions to form a complex defined coacervates that has been studied to assess the controlled release of organic chemicals, volatiles, or proteins and is considered interesting for aqua-feed applications [39]. However, in our study biocomposites made with both low- and high-esterification pectins lost consistency after a few hours of immersion. Since these biocomposites were actively grazed by sea urchins despite their poor consistency, we included a second biopolymer in biocomposites along with apple pectins. Unlike gellan-apple pectin biocomposites, those made with agar and apple pectin were appreciated by sea urchins. Biocomposites made with agar and low-esterification apple pectin released a smaller quantity of nutrients and showed better consistency after 48 hours of immersion in seawater in the presence of sea urchins than high-esterification apple pectin. Therefore, agarapple pectin (low esterification) biocomposites were selected for the trial in the rearing system.

The feasibility of agar as a binder agent for sea urchin feed pellets has been under scrutiny for a long time. Fabbrocini et al. [11] tested the effectiveness of agar-based pellets for gonad growth and gamete production in Paracentrotus lividus with positive results. In biocomposites submerged in seawater in the absence of sea urchins, swelling and nutrient loss were minimal regardless of the type of binder employed. Swelling did not exceed $2 \%$ even after 14 days in seawater and regarding nutrient loss even the worst-performing biocomposite (agar high-esterification pectin, A-AP(he)) did not release more than $2 \%$ of its nutrients. Moreover, there is much variation in the literature concerning the methods employed to measure water stability with respect to the amount of water in which pellets are placed, temperature, time intervals and methods of pellet drying after incubation in water [17]. Thus, given the ample variation in feed ingredients, amount of binders included and manufacturing techniques, it is hard to conclude that one binder is better than another with respect to its stability in water. Therefore, nutrient composition and the percentage and type of binder(s) employed to manufacture sea urchin feed need to be calibrated to suit the species and rearing conditions.

In addition to nutrient composition, palatability is also a key 
concern in the formulation of artificial feed, as it stimulates eating activity and therefore the ingestion rate [40]. Sea urchins have clear feeding preferences both in the field and in confined conditions $[14,41,42]$. In our experiments Paracentrotus lividus specimens actively grazed on some biocomposites (Agar and Agar-low esterification apple pectin) but were not attracted by others (for example alginic acid and gellan-based biocomposites). Thus, since the biocomposites had the same feed composition, it can be inferred that was the type of biopolymer to influence the attractiveness. Biocomposite consistency did not seem to influence feed preference, as sea urchins grazed equally on consistent (agar) and non-consistent (low-esterification apple pectin and citrus pectin) biocomposites, and were not attracted by gellan-based biocomposites, irrespective of their consistency. Such wavering behavior seems to be in agreement with previous studies carried out on the feeding habits of sea urchins $[43,44]$.

In our study, biocomposites prepared with alginic acid and gellan were not eaten by Paracentrotus lividus. Although alginatecontaining pellets were successfully used by Pearce et al. [26], on Strongylocentrotus droebachiensis, Klinger and Lawrence [45] observed that alginate compounds were not phagostimulatory for Lytechinus variegatus, and this is also probably the case with Paracentrotus lividus. Moreover, gellan is not of plant but bacterial origin, and therefore it may not be detected by sea urchins, who are assumed to recognize food by olfaction and taste [44].

Nutrient loss from biocomposites does not seem to be correlated to attractiveness either. Indeed, agar plus low-esterification apple pectin and agar plus high-esterification apple pectin were similarly appreciated by sea urchins, although the pattern of nutrient loss was markedly different, especially in the first few days of water immersion. On the other hand, the slow-moving habits of sea urchins give them high sensitivity in detecting the concentration profiles of chemical plumes [46], so it may be assumed that even when the release of nutrients (and potentially the release of attractant compounds) is limited they are still able to record it.

At the end of the rearing trial in the urchins fed on Agar biocomposite an increase in GI values was observed as well as a slight progression in the reproductive stages, even if less marked than that obtained in the same rearing conditions using a commercial pellet [15]. On the other hand, when the aim of the rearing is not the production of viable gametes, but the obtaining of tasty gonads, a slow progression in the reproductive cycle would facilitate synchronization of the gonads of the reared specimens to the desired reproductive condition.

\section{Conclusion}

In conclusion, among the tested biopolymers, agar has promising features as a binder in the preparation of formulated diets for the sea urchin Paracentrotus lividus. Alone or in combination with apple pectin (low esterification), it produces biocomposites that were completely eaten within three days, thus reducing to a negligible level the amount of wasted food. This property, together with limited nutrient loss, are key objectives in feed manufacturing, as they reduce the amount of waste and nutrient dispersal in the rearing system. Thus, the minimization in food waste is the main strength of these composites that makes up for the cost of biopolymers when working in small-scale laboratory. Moreover, the binders that gave the best results, that is agar and pectin, are available at competitive price if purchased for medium-large scale production. Finally, the use of binders to generate biocomposites allows the inclusion in the formulated feed of a wide range of nutrient factors according to the specific rearing needs, making them a promising starting point for the formulation of innovative and highly versatile formulated feed in both small and large scale rearing systems.

\section{Acknowledgements}

The authors wish to thank Ms M. M. A. Maselli (CNR-ISMAR, Lesina) for the sea urchin rearing system management and Herbstreith \& Fox Pektin-Fabriken, Neuenbuerg, Germany for having kindly donated the pectins.

\section{References}

1. Pearce CM, Daggett TL, Robinson SMC (2004) Effect of urchin size and diet on gonad yield and quality in the green sea urchin (Strongylocentrotus droebachiensis). Aquaculture 233: 337-367.

2. Otero-Villanueva M, Kelly MS, Burnell G (2004) How diet influences energy partitioning in the regular echinoid Psammechinus miliaris; constructing an energy budget. J Exper Mar Biol Ecol 304: 159-181.

3. Schlosser SC, Lupatsch I, Lawrence JM, Lawrence AL, Shpigel M (2005) Protein and energy digestibility and gonad development of the European sea urchin Paracentrotus lividus (Lamarck) fed algal and prepared diets during spring and fall. Aquac Res 36: 972-982.

4. Azad AK, Pearce CM, McKinley RS (2011) Effects of diet and temperature on ingestion, absorption, assimilation, gonad yield, and gonad quality of the purple sea urchin (Strongylocentrotus purpuratus). Aquaculture 317: 187196.

5. Hammer H, Hammer B, Watts S, Lawrence A, Lawrence J (2006) The effect of dietary protein and carbohydrate concentration on the biochemical composition and gametogenic condition of the sea urchin Lytechinus variegatus. J Exp Mar Boiol Ecol 334: 109-212.

6. Mark D Cyrus, John J Bolton, Lourens De Wet, Brett M Macey (2013) The development of a formulated feed containing Ulva (Chlorophyta) to promote rapid growth and enhanced production of high quality roe in the sea urchin Tripneustes gratilla (Linnaeus). Aquac Res 45: 159-176.

7. James P, Siikavuopio SI (2012) The effect of continuous and intermittent feeding regime on survival and somatic and gonad growths of the sea urchin, Strongylocentrotus droebachiensis. Aquaculture 364-365: 173-179.

8. Spirlet C, Grosjean P, Jangoux M (2001) Cultivation of Paracentrotus lividus (Echinodermata: Echinoidea) on extruded feed: digestive efficiency, somatic and gonadal growth. Aquac Nutr 7: 91-99.

9. Cook EJ, Kelly MS (2007) Effect of variation in the protein value of the red macroalga Palmaria palmata on the feeding, growth and gonad composition of the sea urchins Psammechinus miliaris and Paracentrotus lividus (Echinodermata). Aquaculture 270: 207-217.

10. Symonds RC, Kelly MS, Caris-Veyrat C, Young AJ (2007) Carotenoids in the sea urchin Paracentrotus lividus: Occurrence of 9'-cis-echinenone as the dominant carotenoid in gonad colour determination. Comp Biochem Physiol 148B: 432-444

11. Fabbrocini A, Volpe MG, Di Stasio M, D’Adamo R, Maurizio D, et al. (2012) Agar-based pellet as feed for sea urchins (Paracentrotus lividus): rheological behaviour, digestive enzymes and gonad growth. Aquac Res 43: 321-331.

12. Fabbrocini A, D'Adamo R (2011) Gamete and embryos of sea urchins (Paracentrotus lividus Lmk 1816) reared in confined conditions: their use in toxicity bioassays. Chem Ecol 27: 105-115. 
13. Bulleri F, Benedetti-Cecchi L, Cinelli F (1999) Grazing by the sea urchin Arbacia lixula L. and Paracentrotus lividus Lam. in the Northwest Mediterranean J Exp Mar Biol Ecol 241: 81-95

14. Peirano A, Niccolai I, Mauro R, Nike Bianchi C (2001) Seasonal grazing and food preference of herbivores in a Posidonia oceanica meadow. Sci Mar 65 367-374.

15. Fabbrocini A, D'Adamo R (2010) Gamete maturation and gonad growth in fed and starved sea urchin Paracentrotus lividus (Lmk, 1816). J Shellfish Res 29: 1051-1059.

16. Spirlet C, Grosjean P, Jangoux M (1998) Optimizing food distribution in closed-circuit cultivation of edible sea urchins (Paracentrotus lividus: Echinoidea). Aquat Liv Res 11: 273-277.

17. Paolucci M, Fabbrocini A, Volpe MG, Varricchio E, Coccia E (2012) Development of biopolymers as binders for feed for farmed aquatic organisms, In: Muchlisin ZA (ed) Aquaculture, vol. 1 InTech ISBN 979-953307-107-106.

18. Fernandez C, Pergent G (1998) Effect of different formulated diets and rearing conditions on growth parameters in the sea urchin Paracentrotus lividus. J Shell Res 17: 1571-1581.

19. Daggett TL, Pearce CM, Tingley M, Robinson SMC, Chopin T (2005) Effect of prepared and macroalgal diets and seed stock source on somatic growth of juvenile green sea urchins (Strongylocentrotus droebachiensis). Aquaculture 244: 263-281.

20. Mortensen A, Siikavuopio SI, Raa J (2004) Use of transglutaminase to produce a stabile sea urchin feed. In: Lawrence JD (ed) Sea UrchinsFisheries and Ecology, DEStech Publications Inc, Landcaster, PA, USA, pp 203-213. ISBN 13 978-1-932078-32-39.

21. Barker MF, Bremer P, Silcock P, Delahunty C, Sewell M (2006) Enhancement of yield and quality of Evechinus chloroticus roe through controlled diet. $J$ Shell Res 25: 711.

22. Kennedy EJ, Robinson SMC, Parsons GJ, Castell JD (2007) Effects of dietary minerals and pigment on somatic growth of juvenile green sea urchins, Strongylocentrotus droebachiensis. J World Aquac Soc 38: 36-48.

23. Phillips K, Bremer P, Silkock P, Hamid N, Delahunty C, et al. (2009) Effect of gender, diet and storage time on the physical properties and the sensory quality of sea urchin (Evechinus chloroticus) gonads. Aquaculture 288: 208215

24. Barker MF, Keogh JA, Lawrence JM, Lawrence AL (1998) Feeding rate, absorption efficiencies, growth, and enhancement of gonad production in the New Zealand sea urchin Evechinus chloroticus Valenciennes (Echinoidea: Echinometridae) fed prepared and natural diets. J Shell Res 17: 1583-1590.

25. Akiyama T, Unuma T, Yamamoto T (2001) Optimum protein level in a purified diet for young red sea urchin Pseudocentrotus depressus. Fish Sci 67: 361 363

26. Pearce CM, Daggett TL, Robinson SMC (2002) Effect of binder type and concentration of prepared feed stability and gonad yield and quality of the green sea urchin, Strongylocentrotus droebachiensis. Aquaculture 205: 301 323.

27. Volpe MG, Malinconico M, Varricchio E, Paolucci M (2010) Polysaccharides as biopolymers for food shelf-life extention. Rec. Patents on Food Nutr Agric 2: $129-139$.

28. Paolucci M, Fasulo G, Volpe MG (2015) Functional biocomposites based on marine polysaccharides for aquaculture applications. Marine drugs 13: $2680-$ 2693.
29. Volpe MG, Monetta M, Di Stasio M, Paolucci M (2008) Rheological behavior of polysaccharide based pellets for crayfish feeding tested on growth in the crayfish Cherax albidus. Aquaculture 274: 339-346.

30. Coccia E, Santagata G, Malinconico M, Volpe MG, Di Stasio M, et al. (2010) Cherax albidus juveniles fed polysaccharide-based pellets: rheological behavior and effect on growth. Freshwater Crayfish 17: 13-18

31. Volpe MG, Varricchio E, Coccia E, Santagata G, Di Stasio M, et al. (2012) Manufacturing pellets with different binders: effect on water stability and feeding response in juvenile Cherax albidus. Aquaculture 324-325: 104-110.

32. Watts SA, Lawrence AL, Lawrence JM (2013) Sea urchins: Biology and Ecology. Chapter 10. Nutrition In: Lawrence JM (ed), Developments in Aquaculture and Fisheries Science, Elsevier 38: 155-169.

33. Glencross BD, Booth M, Allan GL (2007) A feed is only as good as its ingredients a review of ingredient evaluation strategies for aquaculture feeds. Aquac Nutr 13:17-34

34. AOAC Official Method International 18 Revision 22007

35. Spirlet C, Grosjean P, Jangoux M (1998) Reproductive cycle of the echinoid Paracentrotus lividus: analysis by means of maturity index. Inv Reprod Dev 34: 69-81.

36. Akiyama T, Unuma T, Yamamoto T, Furuita H and Konishi K (1997) An evaluation of amino acid sources and binders in semipurified diet for red sea urchin Pseudocentrotus depressus. Fish Sci 63: 881-886.

37. Pearce CM, Daggett TL, Robinson SMC (2002) Effect of protein source ratio and protein concentration in prepared diets on gonad yield and quality of the green sea urchin, Strongylocentrotus droebachiensis. Aquaculture 214: $307-$ 332.

38. Coviello T, Alhaique F, Dorigo A, Matricardi P, Grassi M (2007) Two galactomannans and scleroglucan as matrices for drug delivery: preparation and release studies. Europ J Pharm Biopharm 66: 200-209.

39. Liu LS, Chen G, Fishman ML, Hicks KB (2005) Pectin gel vehicles for controlled fragrance delivery. Drug Deliv 12: 149-157.

40. Dworjanyn SA, Dirozzi I, Wenshan L (2007) The effect of the addition of algae feeding stimulants to artificial diets for the sea urchin Tripneustes gratilla. Aquaculture 273: 624-633.

41. Stimson J, Cunha T, Philippoff J (2007) Food preference and related behaviour of the browsing sea urchin Tripneustes gratilla (Linnaeus) and its potential for use as a biological control agent. Mar Biol 151: 1761-1772.

42. Ferreira Souza C, Santos de Oliveira C, Crespo Pereira R (2008) Feeding preference of the sea urchin Lytechinus variegatus (Lmk, 1816) on seaweeds. Braz J Ocean 56: 239-247.

43. Vergés A, Becerro MA, Alcoverro T, Romero J (2007) Variation in multiple traits of vegetative and reproductive seagreass tissues influences plantherbivore interactions. Oecologia 151: 675-686.

44. Prado P, Heck KL Jr (2011) Seagrass selection by omnivorous and herbivorous consumers: determining factors. Mar Ecol Prog Ser 429: 45-55.

45. Klinger TS, Lawrence JM, Lawrence AL (1994) Digestive characteristics of the sea-urchin Lytechinus variegatus (Lamarck) (Echinodermata: Echinoidea) fed prepared feeds. J World Aquac Soc 25: 489-496.

46. Weissburg MJ, Fenner MC, Pisut DP, Smee DL (2002) Ecological consequence of chemically mediated prey perception. J Chem Ecol 28: 19531970. 